\title{
GÊNERO, GENEALOGIAS \& AS NOVAS FAMÍLIAS
}

\author{
Mariza Corrêa ${ }^{1}$
}

\begin{abstract}
Resumo
Será que as novas famílias que temos estudado ultimamente são tão "novas" assim? Alguns exemplos sobre a história contada por alguns intelectuais ingleses, ou americanos na Europa, ou sobre eles, sugere que arranjos os mais variados são testados há muito tempo por casais ou grupos sociais que, no entanto, ainda se apresentam como "famílias" - e também registram suas genealogias na sua forma mais tradicional, "esquecendo" relações que não tenham dado origem a descendentes, ou, que ainda que o tenham, são relações pouco convencionais. Também vale a pena perguntarmos se a nossa forma tradicional de apresentar genealogias não induz, pela própria estrutura formal por nós aprendida, a esses apagamentos da história.
\end{abstract}

Palavras-chave: Grupo Bloomsbury. Intelectuais ingleses e americanos. Genealogias. Novas famílias.

\section{GENDER, GENEALOGIES \& THE NEW FAMILIES}

\section{Abstract}

Are the new families we are studying now really 'new'? Some historical examples about English and American intellectuals living in Europe suggest that the most varied arrangements were made by couples or social groups that, nevertheless, continued to present themselves as 'families'. And also to document their genealogies in the most traditional form, 'forgetting' the relationships that did not produced descendants or, even if they did, were most unconventional. It is also worth asking if the formal

${ }^{1}$ Professora do Programa de Doutorado em Ciências Sociais e do Núcleo de Estudos de Gênero/ Pagu, Universidade Estadual de Campinas.correa.mariza@uol.com.br 
structure of the genealogies, as we learned to express them, do not induce this erasure of history.

Keywords: Bloomsbury Group. English and American intellectuals. Genealogies. New families.

The world is rather tiresome, I must say - everything at sixes and at sevens - ladies in love with buggers, and buggers in love with womanizers, and the price of coal going up too. Where it will all end?2

Lytton Strachey, 1919

\section{INTRODUÇÃO}

$\mathrm{N}$ 0 ano em que Lytton Strachey escreveu essa carta, ainda estava in vigor na Inglaterra o "Buggery Act", promulgado por Henrique VIII em 1533 e só revogado na Inglaterra em $1967 .{ }^{3}$ A ilegalidade não impedia que políticos, intelectuais ou artistas fossem conhecidos por suas preferências sexuais - mas talvez tenha adiado a publicação de suas cartas, diários e biografias, agora disponíveis. ${ }^{4}$ Lendo esse material sobre as relações de alguns membros da elite inglesa, é possível perceber que coexistiam com essas relações sabidas, mas não

\footnotetext{
${ }^{2}$ Carta de Lytton Strachey para Dora Carrington, 11 de julho de 1919. "Devo dizer que o mundo é bem cansativo - tudo confuso e fora de ordem - senhoras apaixonadas por gays e gays apaixonados por mulherengos, e o preço do carvão também está subindo. Onde isso tudo vai parar?" (GERZINA, 1995, p. 149).

${ }^{3}$ Bugger, segundo os dicionários, pode ser uma palavra derivada de "búlgaro", então sinônimo de herético, e a intenção de Henrique VIII com esse ato era, aparentemente, atingir o clero católico, que até então tinha julgamento privilegiado por cometer "sodomia", tradução da palavra buggery à época. Adam Kuper mostrou num artigo como o mesmo rei foi responsável por legalizar 0 casamento entre primos, proibido pela Igreja, que o considerava incestuoso, através de uma lei promulgada em proveito próprio, já que seu casamento mais recente contrariava essa proibição; em consequência de legislações subseqüentes, entre 1661 e 1908 o incesto não era considerado um delito na Inglaterra (KUPER, 2000). A revogação de 1967 foi em grande parte estimulada pelos casos de delação de homossexuais que, se desde 1861 não mais condenava os homossexuais à morte, ainda os condenava à prisão. Ver o filme de Basil Dearden, Victim (1962), no qual Dirk Bogarde encarna um personagem que é chantageado por ter tido relações com outros homens. Ou a terrível história de Alan Turing (HODGES, 2001).

${ }^{4}$ Ver o prefácio da biografia de Lytton Strachey, de Michael Holroyd (2005), publicada pela primeira vez em 1968, para a repercussão de suas revelações na Inglaterra de então.
} 
explicitadas, muitos casamentos de conveniência, muitas relações adúlteras e, portanto, muitos filhos nascidos fora do "laço conjugal".

Assim, é curioso que tenha sido o antropólogo inglês W. H. R. Rivers que, parecendo ignorar seu contexto social de origem, e as relações por ele estabelecidas com os intelectuais ingleses, quem se empenhou em aperfeiçoar o método genealógico de pesquisa antropológica, em 1910, cuja ênfase era o casamento e a descendência. ${ }^{5}$ Desse método, e da incorporação por Rivers das pesquisas de L. H. Morgan, derivaram quase todas as discussões antropológicas sobre parentesco na Inglaterra. ${ }^{6}$

Num livro de 1969, que se tornou leitura obrigatória de quase todos os estudantes de antropologia da época, e que reunia os artigos de Rivers, a crítica de Kroeber e outros, Roque Laraia dizia na apresentação que o método genealógico "é o instrumento mínimo de trabalho do antropólogo. Representa, em outras palavras, o alfabeto que permite a transcrição da linguagem do parentesco." (LARAIA, 1969, p. 9). 0 livro é uma coletânea de artigos sobre parentesco e, apresentando brevemente o conjunto, diz Laraia sobre o texto de Leach: "A intenção de Leach é a de mostrar que somente com a libertação total dos velhos esquemas, eivados de preconceitos, é que se pode atingir a compreensão de outras sociedades." (LARAIA, 1969, p. 12)

Mais de quarenta anos depois dessa publicação, e ainda que esses textos permaneçam importantes para os estudos antropológicos, uma série de pesquisas

\footnotetext{
${ }^{5}$ William H.R.Rivers (1864-1922), foi também psiquiatra e ficou famoso pelo tratamento sensível dado a soldados sofrendo de neurose de guerra, durante a I Guerra, em contraste com o tratamento brutal de psiquiatras tradicionais que não podiam aceitar a histeria masculina (SHOWALTER, 1987). Um de seus pacientes mais conhecidos, o poeta Siegfried Sassoon (1886-1967) escreveu poemas para ele em reconhecimento pelos seus cuidados. Apesar de sua sensibilidade, Rivers convenceu Sassoon a voltar para a frente de batalha. Revendo o debate Rivers-Kroeber, George Stocking observa: "Raymond Firth achava que a concepção de casamento [de Rivers], de certo modo ingênua e limitada, com o foco 'quase imperativo na legalização das relações sexuais' poderia ter sido influenciado por 'sua condição de solteiro assumido' - ou, como outros sugeriram, pela sua homossexualidade "fechada no armário’." (STOCKING, 1995, p. 198).

${ }^{6}$ Deixo de lado as contribuições de Claude Lévi-Strauss - e dos analistas brasileiros, entre os quais Manuela Carneiro da Cunha e Eduardo Viveiros de Castro - que levaram a discussão para outros patamares. Aqui, lidando com a tradição inglesa, interessa- me entender como uma sociedade que apresentava determinadas características, num determinado momento, pode atribuir a outras sociedades uma grade que sequer servia para ela própria - mas que serviu de parâmetro para os estudos antropológicos por muito tempo.
} 
a respeito de "novas famílias" já ganhou seu lugar nas estantes de antropologia. Não só as genealogias "ocidentais" se tornaram mais complicadas do que previam aqueles modelos - um jornal diário recentemente publicou a genealogia de uma família na qual pai e mãe se separam e se casam de novo, mostrando todas as complicações genealógicas possíveis advindas desses novos "parentes" adquiridos pelos filhos -, como há novos e sofisticados modelos de leitura das genealogias "tradicionais" incluindo o uso do computador.? Essas pesquisas questionam também a heterossexualidade básica do método genealógico, ao mostrar que muitas das "novas famílias" são famílias de homossexuais - gays ou lésbicas que se tornam pais e mães, por adoção, pelo recurso às novas tecnologias reprodutivas, ou pela incorporação de filhos biológicos a novos arranjos familiares. ${ }^{8}$

No entanto, e ainda que sejam diferentes dos pensados por Leach, "velhos esquemas, eivados de preconceitos", permanecem: as genealogias são ainda representadas a partir de uma base heterossexual - mesmo por aqueles que delas participaram enquanto homossexuais, como mostro no primeiro item deste artigo. ${ }^{9}$ Os outros exemplos aqui arrolados são também exemplos históricos que pretendem sugerir não apenas que as "novas famílias" não são tão novas assim,

\footnotetext{
${ }^{7}$ Marcio Silva está trabalhando num desses modelos muito sofisticados que ele apelidou, provisoriamente, de "máquina do parentesco"; ver Dal Poz e Silva (2008). Para uma avaliação mais ampla, histórica, sobre o método genealógico, ver também seu artigo (SILVA, 2010).

${ }^{8}$ Para uma bibliografia abrangente sobre as novas tecnologias reprodutivas, ver Marilyn Strathern (2009); no mesmo número, Martha Ramírez-Gálvez (2009), aponta para a importante questão da medicalização do parentesco. Não vou discutir aqui os desdobramentos genealógicos possíveis em casos mais complexos como, por exemplo, as manipulações genéticas recentemente denunciadas, feitas na clínica dirigida por um dos mais importantes figurantes dessa tecnologia no Brasil, o médico Roger Abdelmassih. Sobre as novas famílias ver entre outros, Erica Souza (2005) e Ana Paula Uziel (2007). Ver também Flavio Luiz Tarnovski (2011). Não vou discutir também as implicações da inclusão/exclusão da noção de raça nas genealogias - ver, por exemplo, o interessante estudo de Roberto Guedes Ferreira (2008), para o qual Bob Slenes chamou a minha atenção. Não só os descendentes mudavam de cor ao longo do tempo, como os próprios integrantes principais das genealogias também iam alterando sua cor conforme ocorriam mudanças sociais. Para uma breve e interessante história sobre a relação entre parentesco e feminismo, ver Claudia Fonseca (2003).

${ }^{9}$ Judith Butler observa que, levando-se em conta "a alegação de que o parentesco tem sido sempre heterossexual", "aqueles que entram nos termos do parentesco como não heterossexuais, só farão sentido se assumirem o papel de Mãe ou de Pai." Acrescento - ou se forem genitores, ainda que não assumam o papel de pais, conforme o primeiro exemplo analisado abaixo. (BUTLER, 2003, p. 251). Para Françoise Héritier, "nenhuma sociedade admite o parentesco homossexual". Citado por Butler (2003, p. 243).
} 
como que, apesar de todos os pesares, a instituição "família" continua a servir de modelo para muitas das inovações inventadas por nós, ao longo do tempo, em termos de relações mais ou menos duradouras. As genealogias, no entanto, como representação privilegiada do parentesco, talvez tenham perdido sua razão de ser na medida em que utilizando suas convenções tradicionais, é impossível retratar algumas das relações aqui abordadas.

\section{Genealogias E SEUS PENETRAS - o CASo Dora}

Dora Carrington (1893-1932) é um caso interessante na cena literária e artística inglesa - quase desconhecida durante um bom tempo, a não ser por sua relação com o historiador inglês Lytton Strachey, o que rendeu muitas fofocas em diários e cartas de literatos ingleses do início do século vinte, e um filme interessante, ${ }^{10}$ começou há alguns anos atrás a ser recuperada como uma artista com estilo próprio, tanto nos museus ingleses como em museus internacionais. Alguns de seus retratos, como o da mãe de Lytton, ou o do próprio Lytton, são notáveis, pelo colorido e pelo detalhe. ${ }^{11}$ Mas aqui, tratando de entender algumas relações familiares do passado que possam mostrar como as novas famílias do século 21 não são tão novas assim, ela nos interessa mais como uma espécie de porta de acesso a três genealogias ilustres, postas lado a lado na introdução de seu livro por um de seus primeiros publicistas, David Garnett. Garnett (1892-1981), novelista e livreiro inglês, tinha sido casado com Rachel Marshall, com quem teve dois filhos. Dois anos depois da morte dela, ele voltou a se casar, com a filha de Vanessa Bell, irmã de Virginia Woolf, Angelica, a cujo nascimento tinha assistido e que era, de fato filha de Vanessa com Duncan Grant, também pintor, como Vanessa, mas que levava o nome do marido de Vanessa - Clive Bell..$^{12}$ Vanessa e Duncan, um

\footnotetext{
${ }^{10}$ Carrington, dirigido por Christopher Hampton, 1995.

${ }^{11} 0$ fato de que Dora era periférica em relação ao grupo de Bloombsbury, do qual Lytton era figura importante, fica claro pela observação de sua biógrafa de que ninguém ficou sabendo onde seu corpo repousava. Ver Gretchen H. Gerzina (1995, p. 301). As reproduções iconográficas dessa edição são, infelizmente, de péssima qualidade. Mas ver os belos retratos de Strachey nas capas da biografia de Holroyd e das cartas de Strachey (LEVY, 2005). Um dos retratos de Duncan Grant de Vanessa é estranhamente reminiscente do da mãe de Lytton feito por Carrington.

${ }^{12}$ Várias fontes citam o comentário referido por uma das biógrafas de Vanessa e Virginia: "Bunny tinha prometido, ao pé do berço de Angelica, zombeteiramente, como pareceu na época, que ele se casaria com a menina quando ela crescesse." (DUNN, 2004, p. 290). Angélica nasceu em 1918 e Garnett casou-se com Ray Marshall em 1921. Considerações sobre a possibilidade de Angelica
} 
hōmossexual conhecido, viveram juntos durante anos, numa parceria artística e afetiva que durou até a morte dela, em 1961, e Angelica só soube a história de seu nascimento quando adulta. ${ }^{13}$

Carrington, que manteve uma relação afetiva com Lytton Strachey e matouse logo em seguida à morte dele, de câncer, sabia de suas relações homossexuais, e casou-se com Ralph Partridge, em parte por insistência de Partridge, e de alguns amigos, como Virginia Woolf, em parte para manter a relação entre os três, prezada por Lytton..$^{14} 0$ casamento durou pouco - e logo Partridge estava tendo um relacionamento com Frances Marshall, cunhada de Garnett. ${ }^{15}$

Na abertura de seu livro sobre Carrington, David Garnett (1970) apresenta as genealogias de três famílias - os Marshall, família de sua primeira esposa, os Stephen, família de Vanessa Bell e de Virginia Woolf, e os Strachey, família de

perder 0 direito à herança dos pais de Clive Bell certamente também foram levadas em conta Vanessa ia todos os anos à casa deles na época de natal, embora detestasse essas visitas, e ambos, ela e Clive, mantiveram a ficção de que Angelica era filha de ambos. Ver as biografias de Duncan Grant e de Vanessa Bell, passim.

${ }^{13}$ Ver Angelica Garnett (1995). Jane Dunn observa que a época imediatamente anterior à sua gravidez de Angelica foi um período de "provações e isolamento para Vanessa, dirigindo uma unidade doméstica grande, sem provisões suficientes e em condições primitivas. Sua relação com Duncan Grant e seu amante na época, David Garnett, conhecido como Bunny pelos amigos, estava difícil. Eles estavam vivendo juntos, Vanessa mantendo a casa, cuidando de seus filhos e pintando, Duncan e Bunny trabalhando nos campos. A paixão e os ciúmes atormentavam os homens, e ambos procuravam consolo em Vanessa. Ela amava Duncan e finalmente estava grávida dele, mas subseqüentes intimidades sexuais the seriam negadas." (DUNN, 2004, p. 158). A relação entre Garnett e Duncan teria durado de 1915 a 1918, mas durante muitos anos depois disso eles mantiveram relações de amizade e suas cartas referem a vida íntima de Duncan, pelo menos. Cf. Spalding (1998). Depois da morte de Vanessa, um antigo amante de Duncan, que estava nos Estados Unidos, voltou a conviver com ele na Inglaterra e ele e sua família (heterossexual) cuidaram dele até sua morte.

${ }^{14}$ De modo análogo ao que faria Bryher mais tarde - ver o segundo exemplo do texto.

${ }^{15}$ Virginia escreveu à sua irmã, em 1921, que estava "por dentro de tudo" em relação ao casamento de Dora com Partridge e que dera "conselhos maternais". No ano seguinte, dizia à irmã que se sentia "levemente responsável por esse casamento". (WOOLF apud NICOLSON; TRAUTMANN, 1976, p. 470, 595). Frances Parrington - sempre apresentada como "a última representante do grupo de Bloomsbury" - já que viveu por mais de cem anos e começou a escrever suas memórias aos 78 anos, contribuiu por sua vez para a disseminação de fofocas, e contra-fofocas, de familiares e amigos, mas sempre negou que Lytton e Partridge tivessem sido amantes. Segundo a biógrafa de Carrington, que cita também o biógrafo de Lytton Starchey, tais rumores eram infundados. Partridge poderia ser um dos "mulherengos" citados por Strachey na epígrafe. 
Lytton - além de uma pequena genealogia de Carrington, mostrando apenas seus pais e irmãos - e sem outras ramificações, como ocorre com as outras (ver em anexo). ${ }^{16}$

Complicadas à primeira vista, já que parecem genealogias "clássicas", ramificando-se em várias gerações, elas, de fato escondem "linhagens femininas" por trás dos nomes masculinos que as encabeçam. Ralph Partridge e David Garnet entraram na família Marshall pelo casamento com as filhas de William Cecil Marshall. ${ }^{17}$ Garnett entrou na família Stephen através de seu casamento com uma neta de Leslie Stephen. Dora - de quem o livro ostensivamente trata - não entrou nem na família Stephen, nem na família Marshall, nem na família Strachey - sua relação com Strachey de fato não é representada na genealogia - embora a de Duncan Grant com Vanessa Bell o seja - já que produziu uma herdeira e futura cônjuge. A única razão para ela, Dora, aparecer em uma das três genealogias foi seu casamento com Ralph Partridge, que veio a se casar com uma senhorita Marshall depois de sua morte.

Ralph Partridge tornou-se pai de Lytton Burgo Partridge, de seu casamento com Frances, que era sobrinho de Garnett, e que veio a se casar com a filha de David Garnett com Angelica, Henrietta. Duncan Grant, pai biológico de Angélica e primo de Lytton Strachey, tornou-se, assim, sogro de seu ex-amante, David Garnett. ${ }^{18} \mathrm{~A}$ relação entre esses dois tampouco é apresentada na genealogia, bem como não são apresentadas as relações de Grant com Adrian Stephen ou com David Garnett - ao passo que as relações heterossexuais de Adrian Stephen e de Oliver Strachey, que se casaram com duas irmãs são devidamente registradas nela.

\footnotetext{
${ }^{16}$ Vale mencionar que à época da publicação do livro, Garnett e Angelica já estavam separados isto é, que sua "anexação" à família Stephen já tinha sido rompida. Para uma amarga descrição de seu casamento, ver Angelica Garnett (1995), que, no entanto, nunca mudou de nome. Frances Spalding diz que "sua [de Bunny] aparição na periferia de Bloomsbury deveu-se muito ao acaso". (SPADING, 1998, p. 159). Quando terminou sua relação com Duncan, Bunny imediatamente iniciou uma relação com uma mulher bem relacionada e anotou em seu diário que "sem ela... eu me sentiria fora de tudo do qual tinha feito parte por tanto tempo." (SPALDING, 1998, p. 216).

${ }^{17}$ Uma terceira Marshall, Julia, irmã de Rachel e de Frances casou-se com um filho de uma irmã de Lytton, Elinor, tornando-se assim sua sobrinha, além de tia de Lytton Partridge.

${ }^{18}$ Duncan Grant parece ser, de fato, o nome ausente ostensivamente mais presente nessas relações familiares - tendo sido amante de seu primo Lytton Strachey, de Maynard Keynes, do próprio David Garnett e de Adrian Stephen, irmão de Virginia e Vanessa, além de ter estabelecido outras parcerias não contabilizadas aqui.
} 
Ao servir de "ponte" entre essas três genealogias - os Marshall, os Stephen e os Strachey - Dora serve também de pretexto às genealogias desenhadas por David Garnett no seu livro sobre ela que, de fato, não pertencia a nenhuma delas. David Garnett não apresenta nem a sua, nem a genealogia de Ralph Partridge - o que faria mais sentido se a perspectiva dele fosse "masculina", isto é, se os dois fossem apresentados como iniciadores de uma família, ou continuadores de outras sobre as quais nada sabemos - e os Strachey só entram na história graças à relação, não oficial, de Lytton com Carrington, bem como os Marshall e os Stephen só entram como doadores de mulheres - a primeira e a segunda mulher de Garnett, respectivamente, Rachel e Angelica, e a segunda mulher de Partridge. Os outros laços familiares não são relevantes para a trajetória genealógica de Carrington, a não ser pelo fato de que, apresentando a família Marshall, a família Stephen, e a família Strachey como entidades englobadoras, Garnett primeiro deixa patente que ele entrou na família Marshall, assim como na família Stephen, e torna evidentes seus laços "de família" com personagens ilustres, como Sir Leslie Stephen ou Virginia Woolf e as relações entre a família Stephem, a família Marshall e a família Strachey.

Olhando com cuidado as genealogias que Garnett apresenta, parece claro, assim, que há dois "penetras" nessas linhagens, que nelas se incorporaram através do casamento com algumas de suas mulheres - ou de suas relações com alguns homens. ${ }^{19}$ Assim, mais do que um exemplo, como os tantos que Kuper (2000) utiliza para mostrar os laços de parentesco da elite inglesa, talvez tenha sido uma imposição quase estrutural que os filhos de ambos - de David Garnett e de Ralph Partridge - tenham casado entre si, quando a filha de Garnett desposou o filho de Partridge. ${ }^{20}$

\footnotetext{
${ }^{19}$ Eles eram "penetras" - ou outsiders - também em outro sentido: ao passo que a maior parte dos integrantes masculinos do Grupo de Bloomsbury fazia oposição à Primeira Guerra, declarando-se "opositores de consciência" para evitar participar dela, Partridge participara com muito vigor e tornara-se major. Nenhum dos dois tampouco pertencera ao grupo dos Apóstolos - Garnett, de fato, tivera uma história estudantil atribulada e nunca estudara em Cambridge.

${ }^{20}$ Cabe mencionar que um irmão de Lytton, Oliver, casou-se com a irmã da esposa de Adrian Stephen - que, como também tinha mantido relações com Duncan Grant alguns anos antes, isso talvez o tornasse "parente" de sua sobrinha Angélica duas vezes em algum outro sistema de parentesco; o mesmo pode-se dizer de Lytton Strachey, que também mantivera um relacionamento com Duncan Grant e que, portanto, seria duas vezes "parente" de Angélica, sua prima.
} 
A explicitação dessas relações invisíveis sugere que as genealogias são sempre coloridas por outras relações, nem sempre aparentes na sua configuração. Já é lugar comum na bibliografia sobre família a observação de que amantes e filhos ilegítimos são comumente "esquecidos" no seu registro - o que nem sempre é o caso em genealogias reais, por exemplo, nas quais tais filhos e tais amantes são mencionados, ainda que não sejam sempre levados em conta em termos de sucessão. ${ }^{21}$ Nesse exemplo, no caso de um artista que era também um notório homossexual - Duncan Grant - que teve relações com vários integrantes de famílias ilustres, ele parece habitar como uma sombra tanto a entrada de Bunny (apelido de infância de David Garnett, pelo qual ele foi conhecido até a idade adulta) como de Partridge às árvores genealógicas de famílias "ilustres", aqui, dada sua relação com Strachey, que teve uma relação com Carrington, que se casou com Partridge.

Além do fato de as referências aos nomes de origem das famílias darem ênfase a ilustres antepassados masculinos, criando a ilusão de uma família já pronta quando Garnett e Partridge entram nelas, ao diluir as mulheres em laços genealógicos mais amplos, nas famílias Marshall e Stephen, as genealogias também ocultam as relações entre alguns homens dessas três famílias - talvez a real razão para que tenham sido apresentadas no livro: se todas as relações genealógicas explicitadas são heterossexuais, ou geram descendentes - inclusive a relação extra-conjugal de Vanessa Bell com Duncan Grant - as relações entre os homens ficam ocultas por trás do emaranhado de ascendentes e descendentes dessas famílias - entre elas, as relações de Garnett com o pai de Angelica.

Ainda que haja relações de parentesco entre alguns dos integrantes das três famílias, essas genealogias são, de certo modo, imaginárias no que diz respeito à presença de Carrington, já que nenhum desses laços genealógicos passa por ela, e mostram como 0 autor, ciente das relações entre homens em alguns desses casos, mas não os expondo ao leitor, escolhe apresentar uma genealogia "clássica", familiar, que quem sabe expressa seu desejo de pertencer a famílias ilustres - e, ao obliterar as genealogias dos dois personagens que, de fato, estabelecem essas relações - Garnett e Partridge - realça também um resultado que talvez pudesse ser estruturalmente esperado, mas que não deixa de ser interessante- 0 casamento entre os seus descendentes.

\footnotetext{
${ }^{21}$ As genealogias da família real inglesa, por exemplo, são particularmente ricas nessas informações, chegando a descendentes "ilegítimos" atuantes na vida pública até os dias de hoje.
} 
Garnett tampouco era parente de Carrington e, ainda que se apresente apenas como "a casual intimate" (GARNETT, 1970, p. xi) dela, fazia parte de um grupo de amigos que a conheceram bem, mas omite na sua apresentação o que a genealogia mostra - que ele tornou-se sogro do filho do viúvo de Dora, além de ter-se tornado seu concunhado. Dora, no entanto, não era nem descendente nem ascendente de nenhum membro dessas três famílias e tampouco tivera relações de afinidade com elas. Seu casamento com Partridge antecedera a relação de afinidade dele com uma Marshall - o que não a tornava parte dessa família. A genealogia, assim, também esfumaça o tempo, como se todos os "parentes" fossem co-presentes na sua representação.

As relações entre "primos" e "sobrinhos", aparentemente bem visíveis nas genealogias, também se tornam quase fictícias se se examina uma fração delas. Duas irmãs Marshall se casam com Garnett e Partrige - assim, o filho de Partridge era primo dos filhos de Garnett. Mas quando Garnett casa pela segunda vez, na família Stephen, que de fato era oficialmente Bell (ao contrário do que ele enfatiza na sua apresentação da "família Stephen"), com uma noiva que de fato era Grant, o filho de Partridge com Frances Marshall era "primo" das filhas de Garnett com Angelica Bell [seus filhos eram Marshall, mas as filhas dele com ela não] - assim como Henrietta Garnett seria "sobrinha" de Partridge, e portanto "prima” de seu marido Lytton Partridge, mas ele, ainda que sobrinho de David Garnett, não era primo das filhas dele com Angelica - que não eram Marshall. Do modo como a genealogia é apresentada, parecem todos aparentados à família Marshal quando, de fato, ao constituir uma nova família, Garnett ainda tinha laços de sangue com os Marshall, mas as filhas de Angelica com ele, não - ainda que fossem meio irmãs de seus filhos anteriores. Assim, a apresentação genealógica embaralha tanto a ascendência de Angelica (Bell) Grant - filha de Duncan Grant, sobrinho da mãe de Lytton Strachey e primo dele, o que torna Angelica também prima de Lytton - como a descendência dele e de Angelica. A apresentação inclui a todos como membros da família Marshall quando, de fato, tratava-se de uma nova família. Laços de afinidade (distintos) são assim transformados em laços de sangue e todos aparentam fazer parte de uma grande família.

Se olhássemos para as relações entre Strachey e Carrington, ou Duncan Grant e Strachey, Adrian Stephen e Duncan Grant, ou Duncan Grant e David Garnett, não teríamos uma genealogia tradicional. Como essas relações seriam representadas? Assim como a relação que conta para o livro de Garnett, a relação 
significativa entre Carrington e Stratchey não pode ser representada, essas também são ocultadas.

Nessa rede de relações há ainda uma peculiaridade: os "casais" ou grupos maiores de pessoas envolvidas com uma família, viviam em casa cujos nomes ficaram desde então vinculados a seus ex-proprietários. A família de origem de Virginia Woolf morou sempre no número 22 de Hyde Park Gate, que abrigou até 17 pessoas, entre membros da família e empregados - incluídos aí os três filhos do primeiro casamento da mãe de Virginia, Julia, e uma filha do primeiro casamento de seu pai, Leslie, além dos quatro filhos de ambos. Não só todos moraram ali até a morte do pai, em 1904, como durante muitos anos - entre 1882 e 1894 passaram o verão na Talland House, na Cornualha. Virginia mais tarde chamaria sua primeira casa, em Sussex, de Little Talland House. ${ }^{22}$

Depois da morte do pai, Vanessa, Virginia e seu irmão Thoby se mudaram para Gordon Square, 46, em Bloomsbury - região que deu origem ao nome do grupo que se reuniu desde então em torno dos irmãos, muitos deles colegas de Thoby. ${ }^{23}$ Thoby morreu em 1906 e Vanessa casou-se no ano seguinte com Clive Bell, quando Virginia e seu outro irmão Adrian, mudaram-se, primeiro para uma casa onde viviam só os dois, depois para outra - Brunswick Square, 38 - na qual Virginia era a única mulher. Os outros ocupantes da casa eram Leonard Woolf, Maynard Keynes e seu companheiro, Duncan Grant. Em 1911, Virginia e Vanessa alugaram uma casa em Asheham, na qual Virginia moraria com seu marido, Leonard Woolf, alternando-a com quartos em Londres e as clínicas médicas nas quais esteve internada. Em 1916, Vanessa se muda para Charleston, em Sussex, onde viveu com Duncan Grant, e seus filhos, até morrer e que mantém ainda hoje uma coleção das pinturas e objetos de arte de ambos. Mas conviveu também,

\footnotetext{
${ }^{22}$ Para uma evocação das casas de Virginia e de sua família, e seus ecos nos romances dela, ver Hermione Lee (1999), que também narra uma visita saudosa dos filhos, e da própria biógrafa, à Talland House.

${ }^{23} 0$ Bloombury Group talvez seja a "instituição" inglesa mais estudada nos últimos anos os livros sobre esse grupo se contam às centenas, mas ainda assim os limites de sua rede são inconclusivos. Faziam parte dos primeiros freqüentadores da casa Lytton Strachey, Maynard Keynes, Duncan Grant, Roger Fry, Saxon Sydney-Turner, Clive Bell, Desmond MacCarthy, Morgan Forster, Leonard Woolf, e muitos outros foram sendo acrescidos à lista à medida que a lenda literária crescia, e que novos acompanhantes apareciam. De fato, o nome parece referir uma ampla rede de amigos de Virginia e Vanessa, o que podia incluir Bernard Shaw, Dora Carrington, David Garnett, Bertrand Russell, etc.
} 
durante toda a vida, com o marido, Clive Bell, e outros amigos, tanto em Charleston quanto em Gordon Square, 46.

Em 1915, Virginia e Leonard alugaram a Hogarth House, em Richmond, cujo nome deu origem à editora que eles fundaram logo em seguida, a Hogarth Press, que publicou desde então todos os trabalhos de Virginia e de vários de seus amigos, e que contou com a colaboração de Vanessa Bell e de Dora Carrington na feitura de suas capas.

Todos esses endereços, desde então famosos na literatura, formavam assim a base física desse cluster que era 0 grupo de Bloombury. ${ }^{24}$ De fato, todas essas casas eram unidades domésticas compartilhadas, nas quais todos se encontravam com todos, como se fizessem parte de uma grande família. E além de todos se ajudarem mutuamente, os que tinham mais dinheiro ajudando os que tinham menos, e também ajudando a impulsionar suas carreiras, também, em grupos cuja composição variava, faziam juntos freqüentes viagens ao exterior. ${ }^{25}$

Numa vida rica em transações homossexuais, Litton Strachey manteve uma relação estável com Dora Carrington; Duncan Grant, por sua vez, e apesar de suas transações terem incluído homens e mulheres, manteve uma relação também estável com Vanessa Bell e com o poeta Paul Roche, quando jovem e depois da morte dela, e até a sua própria morte em 1978. Duncan, Vanessa e Clive

\footnotetext{
${ }^{24}$ Resumindo as relações entre seus membros - mas sem acrescentar Carrington ou Duncan Grant à única genealogia desse capítulo - Adam Kuper prefere o termo "rede" para designar os membros do Bloomsbury Group. Como sua ênfase no restante do livro é no casamento entre primos, sua análise parte da irmandade dos membros dos Apóstolos, sociedade secreta de Cambridge à qual quase todos os seus membros masculinos pertenceram, para postular uma relação metafórica entre seus integrantes. Assim fazendo, deixa de enfrentar o problema de como incluir, nas representações genealógicas, as relações dos não casados - ainda que as considere no texto - como Carrington e Duncan Grant, sem falar nas relações homossexuais entre inúmeros de seus membros e que, claro, não deixaram descendentes. Essa relação metafórica, ou fictícia, é o que propicia essas manipulações da genealogia por parte de Garnett que vai incluir vários contraparentes na mesma rede familiar dos Marshall e incluir-se na rede familiar dos Stephen. Quando, de fato, sua inclusão seria na família Bell - ou, mais acuradamente, na família Grant, que só aparece lateralmente incorporada na "família Strachey". A noção de cluster foi apresentada por Diana Balmori e Robert Oppenheimer num artigo de 1979 e parece mais pertinente para tratar das relações entre essas famílias - e entre os membros do grupo - já que havia trocas de favores econômicos e políticos entre eles.

${ }^{25}$ Nas casas alugadas no exterior, especialmente na França, a circulação do grupo entre elas se repetia.
} 
se constituíam, no entanto, como um grupo familiar, cuidando das crianças, viajando juntos e resolvendo os problemas domésticos de suas várias moradias, no interior e em Londres - a despeito das relações que Duncan e Clive mantiveram com outros homens e mulheres.

Se conjugalidade e parentalidade estão hoje presentes explicitamente na discussão dos casais gay, é importante lembrar a existência de exemplos históricos onde essas preocupações já tinham lugar - ver adiante as relações entre H. D. e Bryher e Anne Lister e Ann Walker, por exemplo ${ }^{26}$ - ou não tinham, já que se mantinha uma ficção familiar, conforme expresso nas "famílias" que David Garnett escolhe apresentar como pano de fundo da história de Dora que, ao mesmo tempo, escondem relações afetivas reais.

\section{Os narcisos de Sigmund Freud}

As histórias da família Freud já são muito conhecidas e não vale a pena rememorá-las aqui, ainda que alguns membros da família só recentemente tenham contado sua versão da história - e que a relação de Sigmund com a cunhada ainda cause sensação entre alguns pesquisadores contemporâneos, bem como sua relação com a filha Anna - e a dessa filha com Dorothy Tiffany Burlingham. ${ }^{27}$ Essas relações - ainda que também não possam ser expressas em genealogias - assim como aquelas em que se pode desenhar o percurso de relações de Lou Andreas-Salomé com seu marido e seu amante, amiga íntima de Anna, e como que uma terceira mãe para ela (a primeira sendo Martha e a segunda a tia Minna), também foram relações duradouras, já que a relação entre Anna e Dorothy incorporou os filhos de Dorothy que vinham de seu casamento anterior à mudança para Viena e para a Inglaterra.

Mais interessante para refletir sobre as (im)possibilidades das genealogias em expressarem certos arranjos familiares é o estabelecido entre a poeta americana H.D., ou Hilda Doolitle (1886- 1961) e sua companheira Annie Winifred Ellerman, ou Bryher (1894-1983). H.D., poeta americana, viveu quase toda sua vida na

\footnotetext{
${ }^{26}$ Ver Julio Assis Simões, Isadora Lins França e Marcio Macedo (2010) para uma nota sobre transações e relações e sobre a ênfase na conjugalidade e parentalidade na discussão contemporânea da homossexualidade - ênfase presente nas relações de Anna Freud com Dorothy Burlingham.

${ }^{27}$ Ver, por exemplo, Peter Gay (1989); Elisabeth Young-Bruehl (1992); Lisa Appignanesi e Johnn Forrester (2000); Michael John Burlingham (2002); Lou Andreas-Salomé/Anna Freud (2006); e Sophie Freud (2007).
} 
Europa, com poucas visitas esporádicas aos Estados Unidos e foi paciente de Freud entre os anos 1933 e 1934. 0 pagamento da análise foi feito por Bryher, herdeira de um dos homens mais ricos do Reino Unido, e companheira de H.D. entre 1919 e 1946. A correspondência entre ambas é fascinante, não apenas por revelar um ménage não convencional, como por mostrar uma relação de Freud com sua paciente que também parecia fugir a todas as regras impostas pelo mestre aos seus discípulos. ${ }^{28}$

Em Londres H.D. casou-se com Richard Aldington, poeta e novelista, que conheceu H.D. através de Ezra Pound, com quem ela tivera um romance nos Estados Unidos, em 1913. Os três tinham protagonizado um novo movimento poético o dos Imagistes - desde então. 0 nascimento de uma filha morta em 1915, fez com que as relações entre ambos se tornassem difíceis - aliado à participação de Aldington na Primeira Guerra, da qual ele retornou traumatizado. Ele estimulou um relacionamento entre H.D. e Cecil Gray, crítico musical e compositor, com quem ela teve uma filha em 1919, Perdita. Nesse ano ela conheceu Bryher na Grécia e a ajuda que precisava para cuidar de sua filha - renegada tanto por Aldington, quanto por Gray - também ajudou Bryher a superar seus ímpetos suicidas. Em 1921, Bryher casou-se, por conveniência, com o poeta, novelista e editor Robert McAlmon - responsável pela edição de inúmeros poetas modernistas - de modo a assegurar sua independência dos pais dela e com o compromisso de ajudá-lo nos seus empreendimentos editoriais. Desgostosa com seu alcoolismo, ela se divorciou dele em 1927 e no mesmo ano se casou com Kenneth Macpherson, novelista, cineasta e artista, que tinha sido amante de H.D. entre 1926 e 1930, de quem também ela engravidou, tendo sofrido um aborto. Bryher e ele se tornaram amigos e casaram para permitir a continuação do romance entre ele e H.D - contra o qual a mãe dele se opunha - e ambos adotaram legalmente Perdita, a filha de

\footnotetext{
${ }^{28}$ Ver Susan Stanford Friedman (2002), que editou a correspondência. A autora observa, na sua introdução, que a rede de relações de H.D. conformava "um outro Bloomsbury", citando entre seus integrantes: Ezra Pound, T.S.Eliot, William Carlos Williams, Ford Madox Ford, D.H. Lawrence, Richard Aldington, Rebecca West, Violet Hunt, Mary Sinclair, Dorothy Richardson, Marianne Moore, Robert McAlmond, Mina Loy, Mary Butts, John Cournos, Nancy Cunard, Paul Robeson, Gertrude Stein, Carl van Vetchen, Langston Hughes, Conrad Aiken, Edith Sitwell, Osbert Sitwell, W.B.Pabst, Katherine Burdekin, Havelock Ellis e Bryher - que englobava" os expatriados e os centros boêmios de Paris, de Roma, e de Nova York". (FRIEDMAN, 2002. p. xv). Essa rica correspondência também aponta para o fato de que as pacientes lésbicas de Freud foram subestimadas na história da psicanálise e que, de fato, Sidonie C. não foi a "única"” paciente homossexual de Freud. Cf. Rieder e Voigt (2008).
} 
H.D. Depois de 1930, MacPherson tornou-se amante de vários artistas negros e começou a se distanciar da casa que até então os três, e Perdita, além de vários outros personagens, habitavam. Breyher separou-se dele em 1947, comprando para ele uma vila em Capri.

De 1931 a 1983, Bryher viveu em Kenwin - acópope de seu nome com o de MacPherson (Keneth/Winifred) - na Suíça, com estadias alternadas em Londres, e em vários momentos todos esses personagens se encontravam naquela unidade doméstica. Entusiasta da psicanálise, Bryher pagou o tratamento de vários de seus amigos, tornou-se ela própria amiga de vários psicanalistas, e financiou o tratamento de H.D. com Freud, tendo também contribuído para financiar a retirada de muitos judeus de Viena durante a ascensão do nazismo - inclusive a família da judia vienense Alice Modern, governante de Perdita desde 1932. Perdita, assim, viveu num lar com duas mães e vários "pais" - menos seu pai biológico, que só veio a conhecer em 1948 - e com vários companheiros desses pais, além de sua avó materna, que depois da morte do marido, morou com elas entre 1922 e $1926 .{ }^{29}$

A correspondência do período em que H.D. foi analisada por Freud mostra uma relação cálida entre ambos, e um interesse de parte a parte sobre textos literários, viagens e achados arqueológicos, além de registrar os pequenos presentes de um lado e do outro. ${ }^{30}$ Tais cartas iluminam vários aspectos do cotidiano de Freud, tanto em Viena quanto em uma de suas casas de verão; recebendo, num de seus aniversários, o presente de narcisos, enviados por Bryher, ele a declarou sua flor preferida, ao lado das gardênias - e entregou a H.D. um ramo de orquídeas, das tantas que recebera naquela dia. ${ }^{31}$ No seu último dia de análise com Freud (dezembro de 1934), H.D. levou para Martha um vaso com uma azaléia podada no formato de uma pequena árvore de natal, com flores e botões, e recebeu dele um ramo de laranjeira, com laranjas.

${ }^{29}$ Comparar com a autobiografia de Angelica Bell, ou Grant, ou Garnett - embora a autobiografia de Perdita ainda não tenha sido publicada, foi citada no livro de Friedman.

${ }^{30}$ Ver, por exemplo, as dúvidas de ambas, H.D. e Bryher, sobre se aceitavam ou não a oferta de Freud de dar a Perdita um dos filhotes de seu Chow-Chow. H.D. temia melindrá-lo se recusasse ou que ele voltasse atrás em suas idéias, segundo ela, de que todas as mulheres tinham inveja do pênis, e não apenas as lésbicas. (FRIEDMAN, 2002, carta 120, p. 234 e adiante).

${ }^{31}$ Quando Freud recebeu a visita de Virginia Woolf em Londres, em 1939, ele também a presenteou com um narciso mas, curiosamente, sempre recebia orquídeas no seu aniversário. Numa referência da Wikipedia para narciso, lê-se seu nome científico como bryher daffodil. 
Em 1946, H.D. sofreu um colapso nervoso e se internou numa clínica suíça, à qual voltou, após seu tratamento, em 1953, e onde viveu até 1961, só tendo viajado aos Estados Unidos para conhecer os netos. Perdita se casou, em 1950, com um americano, e teve quatro filhos. Sua autobiografia e a correspondência com sua mãe permanecem inéditas.

\section{FORTUNAS FAMILIARES}

A primeira providência da rica herdeira de Shibden Hall, Anne Lister (1791-1840), ao se mudar para essa propriedade do século quinze na Inglaterra do século dezenove, foi providenciar uma genealogia da sua família - através de uma cópia do testamento do bisavô de seu bisavô. A genealogia - de 1606 a 1840 - é reproduzida por Jill Liddington (1998, p. 5) e mostra também que Anne foi a última descendente da família.

Sua vizinha, Ann Walker (1803-1834), tinha ancestrais menos conhecidos na sua genealogia (de 1665 a 1854), mas, ao contrário da família de Anne, proprietária de terras, pertencia à "elite comercial recentemente enriquecida" (LIDDINGTON, 1998, p. 28) de Halifax. Nenhuma das duas herdeiras era filha dos filhos primogênitos que herdaram as propriedades que passaram às mãos de ambas - o pai de Ann a herdou de seu irmão, ele sim o primogênito, e Anne a herdou do tio, irmão do pai, que não se casou - e que, aparentemente tinha mais medo dos "caçadores de dotes" do que do fato de sua sobrinha ter pendores mais para relações com mulheres do que para relações com homens. Ambas, assim, tornaram-se herdeiras por uma série de circunstâncias que incluíam a morte de irmãos varões ou a falta de herdeiros homens por parte de seus parentes - de certo modo já burlando, a partir daí as convenções familiares da época. Anne tinha tido várias relações homossexuais desde seu tempo de escola, bem conhecidas na sua região, e aparentemente se interessou pela vizinha num misto de atração por ela e por sua fortuna.

Depois de muitas idas e vindas na relação de ambas, que incluíram uma crise nervosa e internação de Ann, as duas trocaram anéis, fizeram testamentos mútuos e Ann mudou-se para Shibden - onde já moravam o pai de Anne e sua irmã, além de meia dúzia de criados, e tratou de incorporar as propriedades de Ann a Shibden. As intrincadas relações políticas e econômicas de Anne incluíam uma série de negócios - inclusive uma mina de carvão que explorava o trabalho de 
crianças - que a levaram diretamente para o centro da vida política conservadora de Yorkshire, na Inglaterra. Incluíram também menções jocosas no jornal local ao seu "casamento" e uma queima em efígie de ambas, mas aparentemente essas manifestações tinham mais a ver com as atitudes férreas de Anne em relação a seus empregados e clientes do que com suas relações com Ann. Festejada como "a primeira lésbica da história", com direito a muitos artigos em revistas especializadas e a um filme da BBC ${ }^{32}$, ela foi conhecida durante muito tempo por um diário de cerca de 26 volumes - estimados em quatro milhões de palavras - que escreveu desde seus quinze anos, no qual contava não só suas aventuras sexuais, como suas aventuras políticas, usando um complicado código que só foi decifrado quase cem anos depois, por um descendente seu, que também se recusou a queimar o diário, como lhe foi aconselhado. 0 diário já mereceu várias exegeses, que não vou recapitular aqui, sugerindo como certas palavras que ela empregava ali deram origem a muitas expressões no mundo queer - e como ela foi uma pioneira na luta das mulheres lésbicas na Inglaterra, ou, pelo menos, uma das primeiras a registrar esse mundo em tantas palavras.

Seu comportamento, de fato, conforme analisado por Liddington, era mais próximo ao de um homem poderoso do que ao de uma mulher - tanto em relação à Ann, como em relação aos seus subordinados, e levanta muitos pontos interessantes para se pensar se a dominação masculina, teorizada por Bourdieu, pode ser chamada de "masculina". Anne era contrária à educação feminina, ao direito ao voto - que ela própria não tinha, embora controlasse os votos de vários de seus agregados e subordinados - e tanto nas cenas sexuais descritas em seu diário, como nas políticas, descrevia-se sempre como o que Bourdieu chamaria de "o homem da casa". Morreu na Rússia, na última viagem que fez com Ann que foi em seguida internada num asilo de loucos, aparentemente por disputas familiares em torno da herança de ambas.

A história delas figura aqui tanto para sugerir que as relações familiares eram mais complexas no passado do que nos acostumamos a pensar, sempre acreditando que acabamos de inventar as mais inovadoras formas de relações humanas no presente, quanto pelo quão curioso é o fato de ambas, Anne e Ann, que não pretendiam casar, nem ter filhos, terem dado tanta importância às suas genealogias, para a qual nenhuma das duas contribuiria com descendentes.

\footnotetext{
${ }^{32}$ Liddington cita também outros romances que a tomaram como personagem, inclusive, aparentemente, Shirley, de Charlote Brontë.
} 
Talvez Firth estivesse certo em sua crítica a Rivers - ou, quem sabe, Rivers estivesse certo sobre a ânsia pelas relações matrimoniais, ou similares a elas. 0 Boston marriage, afinal, tão bem descrito por Henry James, e em terras tão distantes, não estava muito longe desse modelo.

\section{EPÍlogo}

Minha atenção e curiosidade foram despertadas por esses exemplos ao lê-los ao mesmo tempo em que leio a produção contemporânea sobre "as novas famílias" que, afinal, talvez não sejam tão novas assim. E são também apresentados como um desafio aos novos antropólogos para que reinventem o nosso famoso método genealógico. Peter Fry me sugere que, se temos tantos relatos desses tipos é porque esses personagens pertenciam à elite intelectual - e portanto escreviam sobre suas experiências - e que talvez devêssemos pensar um pouco sobre se essas relações não convencionais também estariam presentes em outras classes sociais, citando como exemplo o livro de Jeffrey Weeks e Kevin Porter (1991). É possível, mas isso demandaria uma outra pesquisa.

Num livro muito interessante sobre a sexualidade vitoriana, o jornalista Ronald Pearsal (1971) relata alguns processos de homossexuais que se tornaram famosos - num deles, de cross dressing, os réus foram absolvidos; em outro, o jornalista que os denunciou foi condenado, e em todos eles se tratava de relações inter-classes. Em ambos, os membros da elite envolvidos convenientemente viajaram para 0 exterior na época do julgamento. ${ }^{33}$ Vale a pena lembrar que a primeira namorada de Anne Lister foi "uma garota de cor" (LIDDINGTON, 1998, p. 15), depois declarada insana. Nessas relações inter-classe, no entanto, não se tratava, é claro, de "famílias" - então, por enquanto, só temos os relatos das famílias de elite sobre seus arranjos pouco convencionais. E genealogias tratam, afinal, de "famílias", e, seja como for que elas sejam definidas, o velho método genealógico deixa de cobrir uma parcela importante das relações humanas que pretende retratar. ${ }^{34}$

${ }^{33}$ Ainda que Pearsall dedique um capítulo sobre a sexualidade às "classes menos favorecidas", lá ele só trata de relações heterossexuais.

${ }^{34}$ Agradeço aos vários amigos que leram e comentaram esse texto, a Claudia Fonseca, Richard Miskolci, Adriana Piscitelli e Peter Fry, especialmente, e a Mauro Almeida, que está tentando construir uma genealogia que seja mais adequada aos dados empíricos aqui utilizados. Claudia lembrou várias histórias “picantes" sobre Angélica Garnett, que circulavam na França quando ela 


\section{REFERÊNCIAS}

ANDREAS-SALOMÉ, Lou; FREUD, Anna. À l'ombre du père. correspondance 19191937. Paris: Hachette, 2006.

APPIGNANESI, Lisa; FORRESTER, John. Freud's women. NewYork: Other Press, 2000.

BALMORI, Diana; OPPENHEIMER, Robert. Family clusters: generational nucleation in nineteenth-century Argentina and Chile. Comparative Studies in Society and History, Cambridge, v. 21, n. 2, p. 231-261, 1979.

BURLINGHAM, Michael J. Behind Glass: a biography of Dorothy Tiffany Burlingham. New York: Other Press, 2002.

BUTLER, Judith. 0 parentesco é sempre tido como heterossexual? Cadernos Pagu, Campinas, n. 21, p. 219-260, 2003.

DAL POZ, João; SILVA, Marcio Ferreira da. Informatizando o método genealógico: um guia de referência para a máquina do parentesco. Teoria e Cultura, Juiz de Fora, v. 3, n. 1/2, p. 63-78, 2008.

DUNN, Jane. Virginia Woolf and Vanessa Bell: a very close conspiracy. London: Virago Press, 2004.

FERREIRA, Roberto Guedes. Estratégias de mobilidade social em sociedades escravistas: uma análise comparada (Porto Feliz/São Paulo/Brasil e Tribee/São Domingos), Séc. XVIII e XIX. Fronteiras, Dourados, v. 10, n. 18, p. 51-93, 2008.

FONSECA, Claudia. De afinidades a coalizões: uma reflexão sobre a "transpolinização" entre gênero e parentesco em décadas recentes da antropologia. Ilha, Florianópolis, v. 5, n. 2, p. 5-31, 2003.

FREUD, Sophie. Living in the shadow of the Freud Family. London: Praeger, 2007.

FRIEDMAN, Susan Stanford. Analyzing Freud: letters of H.D., Bryher, and their circle. NewYork: New Directons Books, 2002.

GARNETT, Angelica. Deceived with kindness: a bloomsbury childhood. Londres: Random House, 1995.

morou lá; Adriana sugere, inspirada num texto de Daniel Miller (2007), que talvez o que seja novo nessas novas famílias seja o fato de que elas agora se formalizam como famílias, até juridicamente. 
GARNETT, David. Carrington: letters and extrats from her diares. New York: Ballantine Books, 1970.

GAY, Peter Freud: uma vida para o nosso tempo. São Paulo: Companhia das Letras, 1989.

GERZINA, Gretchen H. Carrington: a life. New York: Norton, 1995.

HODGES, Andrew. Turing: um filósofo da natureza. São Paulo: UNESP, 2001.

HOLROYD, Michael. Lytton Strachey: the new biography. New York: W.W. Norton \& Company, 2005.

KUPER, Adam. Le marriage entre cousins et l'inceste du deuxième type chez lês intellectuels de l"Anglaterre victorienne. In: JAMARD, Jean-Luc; TERRAY, Emmanuel; XANTHAKOU, Margarita (Ed.). En substances: textes pour Françoise Héritier. Paris: Fayard, 2000.

LARAIA, Roque de Barros (Org.). Organização social. Rio de Janeiro: Zahar, 1969.

LEE, Hermione. Virginia Woolf. New York: Vintage Books, 1999.

LEVY, Paul. The letters of Lython Strachey. New York: Straus and Giroux, 2005.

LIDDINGTON, Jill. Female fortune: land, gender and authority: the Anne Lister diaries and other writings, 1833-1836. London: Rivers Oram Press, 1998.

MILLER, Daniel. What is a relationship? is kinship negotiated experience? Ethnos, Stockholm, v. 72, n. 4, p. 535-554, 2007.

NICOLSON, Nigel; TRAUTMANN, Joanne (Ed.). The letters of Virginia Woolf: 1912-1922. New York: Harvest, 1978. v. 2.

PEARSALL, Ronald. The Worm in the Bud: the world of victorian sexuality. London: Penguin Books, 1971.

RAMÍREZ-GÁLVEZ, Martha. Corpos fragmentados e domesticados na reprodução assistida. Cadernos Pagu, Campinas, n. 33, p. 83-115, 2009.

RIEDER, Ines; VOIGT, Diana. Desejos secretos. a história de Sodonie C., a paciente homossexual de Freud. São Paulo: Companhia das Letras, 2008.

SHOWALTER, Elaine. The female malady: women, madness and english culture, 1830-1980. London: Penguin Books, 1987.

SILVA, Marcio Ferreira da. 1871: o ano que não terminou. Cadernos de Campo, São Paulo, ano 19, n. 19, p. 323-338, 2010. 
SIMÕES, Julio Assis; FRANÇA, Isadora Lins; MACEDO Marcio. Jeitos de corpo: cor/ raça, gênero, sexualidade e sociabilidade juvenil no centro de São Paulo. Cadernos Pagu, Campinas, n. 35, p. 37-78, 2010.

SOUZA, Érica. Necessidade de filhos: maternidade, família e (homo) sexualidade. 2005. Tese (Doutorado em Ciências Sociais) - Universidade Estadual de Campinas, Campinas.

SPADING, Frances. Duncan Grant: a biography. Londres: Pimlico, 1998.

STOCKING JUNIOR, George W. After Tylor: british social anthropology 1888-1951. Madison: The University of Wisconsin Press, 1995.

STRATHERN, Marilyn. A antropologia e o advento da fertilização In Vitro no Reino Unido: uma história curta. Cadernos Pagu, Campinas, n. 33, p. 9-53, 2009.

TARNOVSKI, Flavio Luiz. Les coparentalités entre gays et lesbiennes en France: le point de vue des pères. Vibrant, v. 8, n. 2, p. 138-163, 2011.

UZIEL, Anna Paula. Homossexualismo e adoção. Rio de Janeiro: Garamond, 2007.

WEEKS, Jeffrey; PORTER, Kevin. Between the acts: lives of homosexual men: 1885-1967. London: Rivers Oram Press, 1991.

YOUNG-BRUEHL, Elisabeth. Anna Freud: uma biografia. Rio de Janeiro: Imago, 1992. 

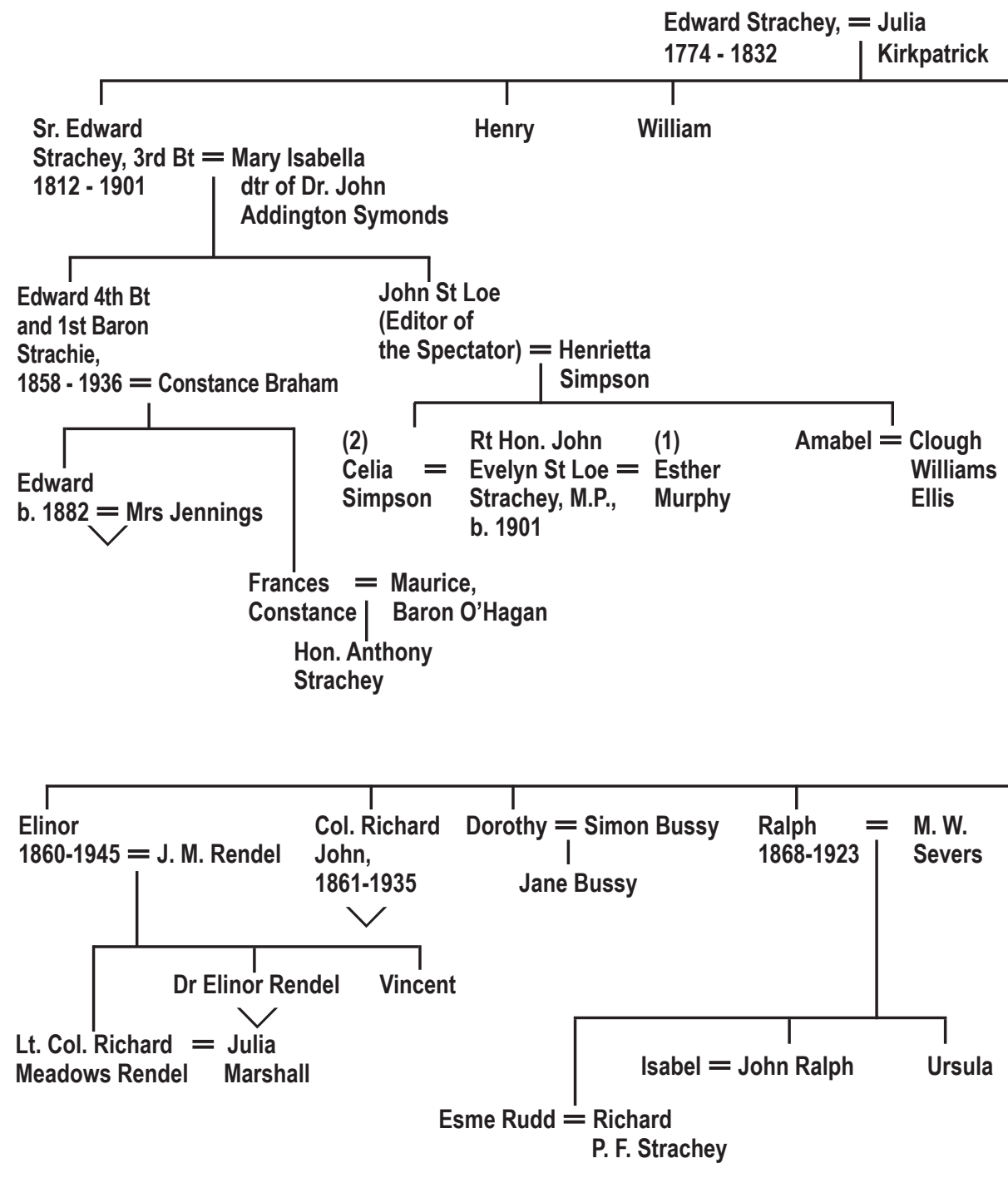

\section{CARRINGTON FAMILY}

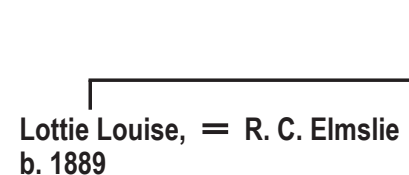

\begin{tabular}{l|l} 
Samuel Carrington $=$ Charlotte \\
1832-1919 & $\begin{array}{l}\text { Houghton } \\
\text { m. } 1888\end{array}$
\end{tabular}




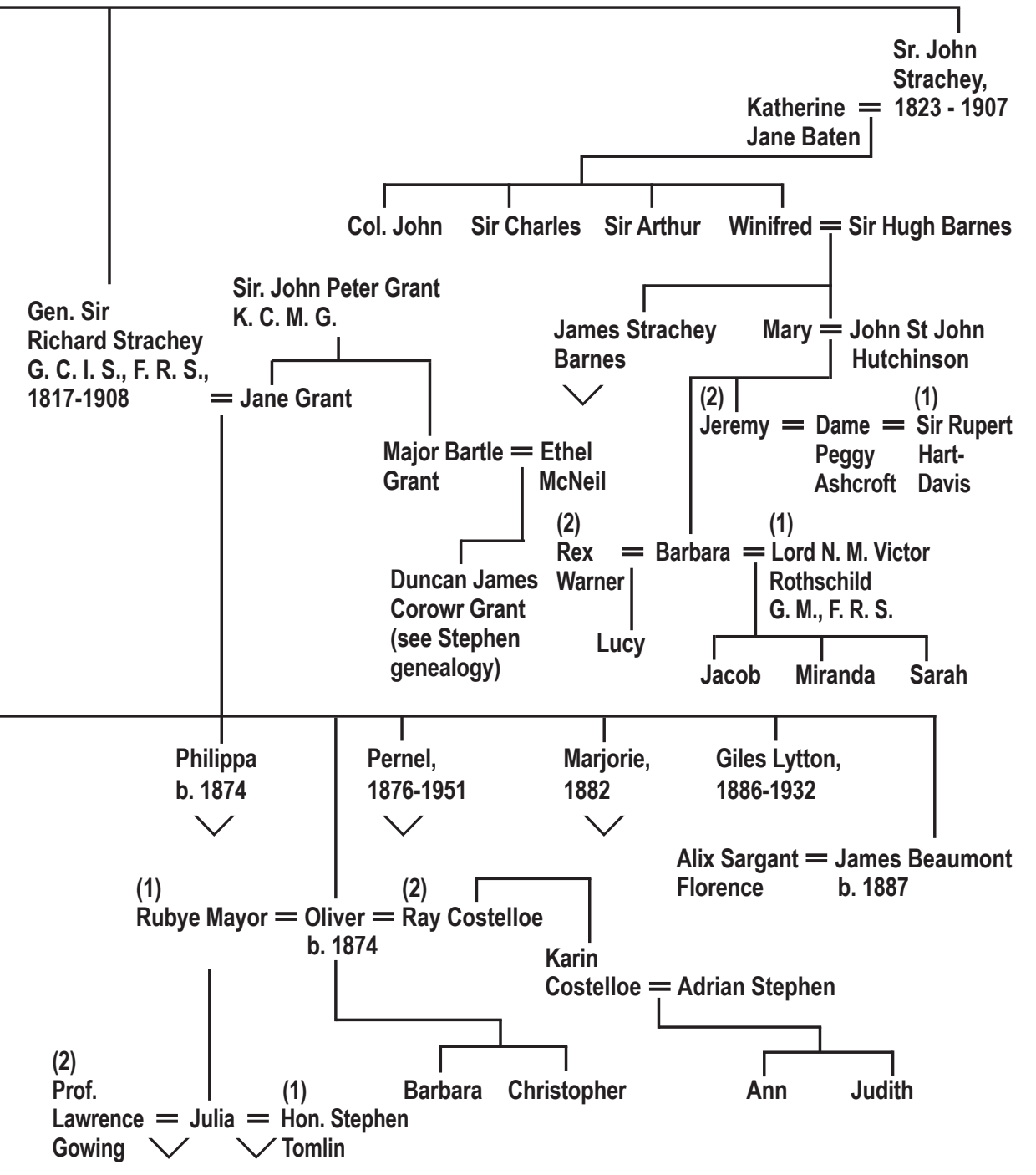

(1)

(2)

Dora Houghton, = R. Partridge, = Frances Marshall, $\quad$ Noel Lewis, = Catherine 1893-1932, $\begin{array}{llll}\text { d. } 1960 & \text { b. } 1900, & \text { b. } 1894 & \text { Alexander, }\end{array}$ m. 1922

m. 1933

m. 1925 


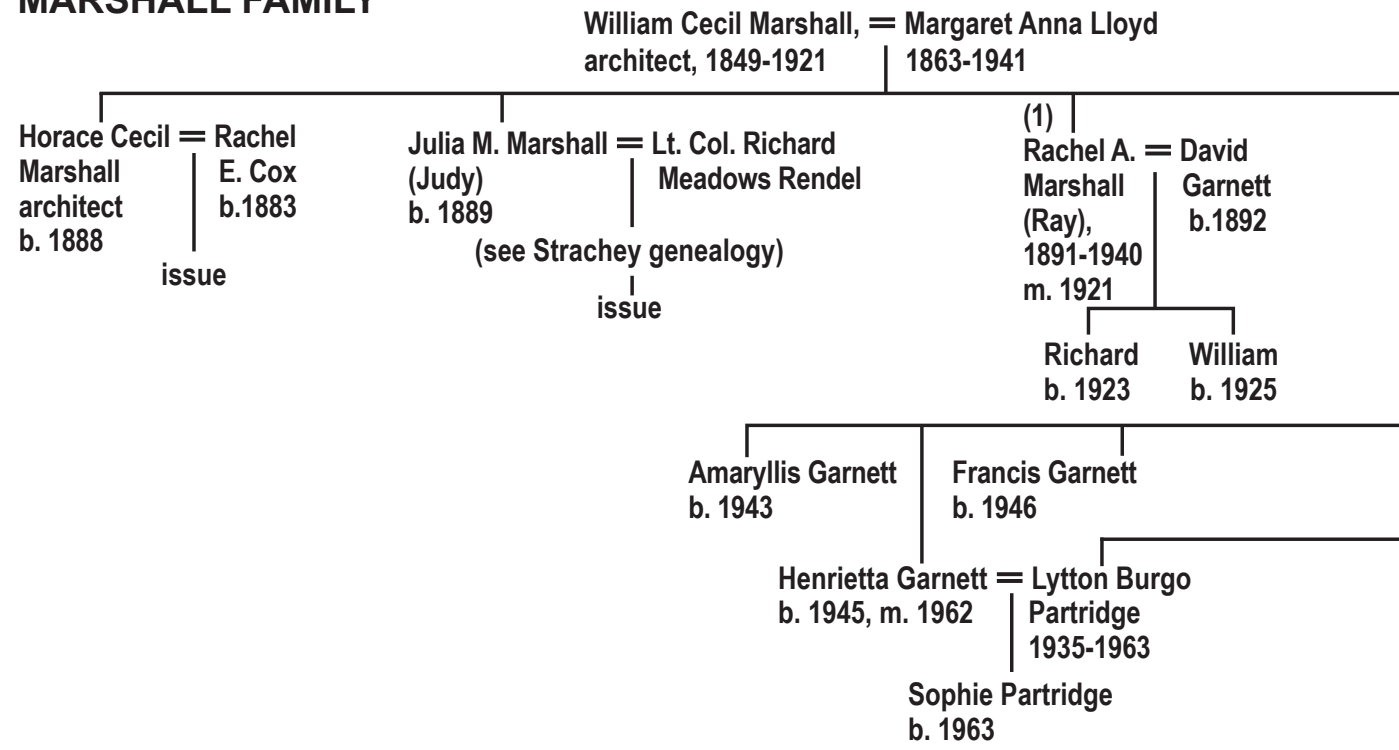

\section{STEPHEN FAMILY}

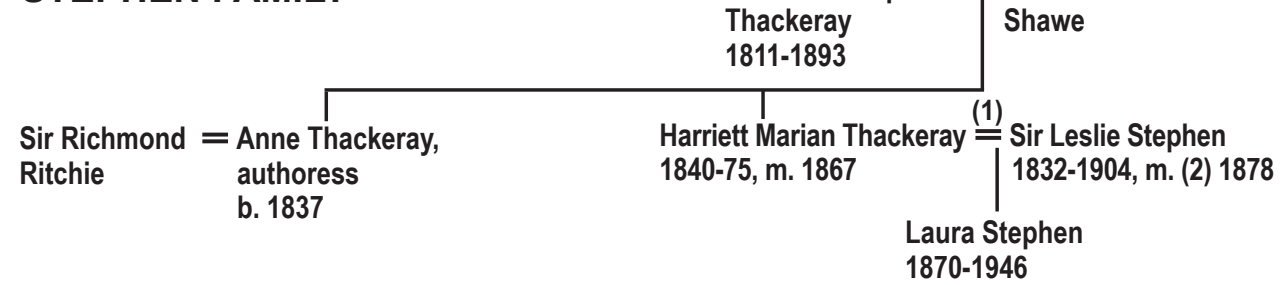

Thoby Stephen 1880-1906

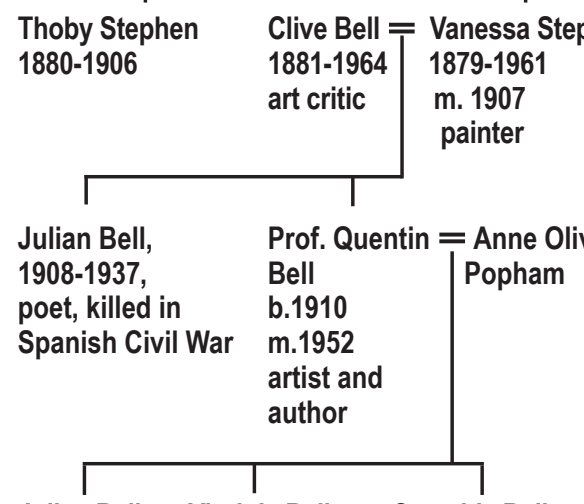

Julian Bell, Virginia Bell, b, 1952

b. 1955
Prof. Quentin = Anne Olivier

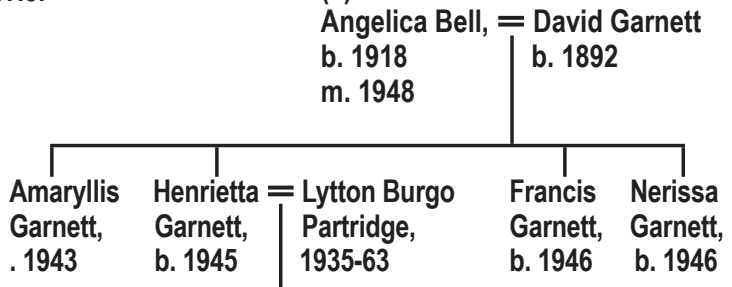

Virginia Stephen $=$ Leonard Woolf 1882-1941 1880-1969

Sophie Partridge, b. 1963 
(2)

$=$ Angelica

Bell

b. 1918

m. 1942
Eleanor Marshall, $=$ Ambrose Price

b. 1897<smiles>[SiH3][SiH3]</smiles>

(2)

(1)

Francis Marshall $=$ Ralph Partridge $=$ Dora de Houghton

b. 1900, m. 1933

1894-1960

Carrington

1893-1932, m. 1922

Marjorie $=$ Thomas H. $=$ Nadine

Thompson Marshall Hambourg

Nerissa Garnett

b. 1893

Mark Marshall

b. 1946

$\stackrel{(2)}{=}$ Julia Prinsep $\stackrel{(1)}{=}$ Herbert

Jackson

d. 1895

Duckworth

m. 1867

d. 1870

Gerald Duckworth, publisher 1870-1937

Sir George = Lady

Duckworth Margareth 1868-1934 Herbert

issue
Estela Duckworth = J. H. Wills, M. P. 1869-97

Rachel Costelloe $=$ Oliver Strachey

(Ray)

(see Strachey genealogy)

= Rachel A. Marshall

(Ray)

1891-1940

m. 1921
Dr. Adrian Stephen, = Dr. Karin 1883-1948 psychoanalyst
Costelloe psychoanalyst
Ann Stephen $=$ R. M. L. Synge, F. R. S. Judith Stephen $=$ Nigel

b. 1915

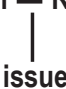

b. 1918

Henderson

\footnotetext{
Richard = Jane

Garnett Dickins

William $=$ Linda

b. 1923

Garnett, Burt

b. 1925
} 